\title{
Article
}

\section{'Dr Google' will see you nowl A review of online consumer information about anticoagulant and antithrombotic medication for prevention of recurrent stroke}

Gibson, Josephine, Ellis, R.K. and Jones, Stephanie Available at http://clok.uclan.ac.uk/25764/

Gibson, Josephine ORCID: 0000-0002-3051-1237, Ellis, R.K. and Jones, Stephanie ORCID: 0000-0001-9149-8606 (2019) 'Dr Google' will see you now! A review of online consumer information about anticoagulant and antithrombotic medication for prevention of recurrent stroke. Journal of Consumer Health on the Internet, 23 (1). pp. 1-12. ISSN 1539-8285

It is advisable to refer to the publisher's version if you intend to cite from the work. http://dx.doi.org/10.1080/15398285.2019.1570800

For more information about UCLan's research in this area go to

http://www.uclan.ac.uk/researchgroups/ and search for < name of research Group>.

For information about Research generally at UCLan please go to http://www.uclan.ac.uk/research/

All outputs in CLoK are protected by Intellectual Property Rights law, including Copyright law. Copyright, IPR and Moral Rights for the works on this site are retained by the individual authors and/or other copyright owners. Terms and conditions for use of this material are defined in the policies page. 
'Dr Google' will see you now! A review of online consumer information about anticoagulant and antithrombotic medication for prevention of recurrent stroke.

JME Gibson, School of Nursing, University of Central Lancashire, Preston, PR1 2HE, UK

RK Ellis ${ }^{1}$, School of Life Sciences \& Education, Staffordshire University, Stoke-on-Trent, ST4 2DE, UK.

SP Jones, School of Nursing, University of Central Lancashire, Preston, PR1 2HE, UK

Running title: Online information about stroke medication

Keywords: Online information; stroke; medication; laypersons.

\footnotetext{
${ }^{1}$ Formerly at School of Psychology, University of Central Lancashire, Preston, PR1 2HE, UK

[Type here]
} 


\section{Abstract}

Stroke survivors increasingly use the internet to access health information. The aim of this study was to evaluate the quality of online information about anticoagulant and antiplatelet medication in stroke. 100 online information sources and 50 online news articles about anticoagulants and antiplatelets after stroke were accessed using Google in June-July 2016. Readability, overall quality, and language about prevention, risk, emotive terms, and shared decision-making were evaluated using SMOG and DISCERN tools. Most online information was from national health service $(27 / 100)$ or charitable (24/100) sources, or from tabloid newspapers' websites (25/50). Median reading age for materials was $17-18$ years. Quality scores were typically 3/5 with only 5 of 16 criteria scoring highly. Stroke risk reduction was typically described in absolute terms with little use of numerical or graphical data. Emotive language was frequently used, particularly in news articles. Shared decisionmaking was supported mainly by materials from charitable sources. This study has shown that online information about anticoagulant and antiplatelet medication after stroke requires high levels of literacy, and is often unreliable, poor quality and emotionally laden. People working with stroke survivors should facilitate access to accurate, unbiased and readable materials to promote shared decision making about medications.

[Type here] 


\section{Introduction}

In long-term conditions, such as after stroke, it is estimated that around $50 \%$ of prescribed medication doses are either omitted or taken incorrectly [1]. After ischaemic stroke, several longterm medications, including either antithrombotic medications (or, for those with atrial fibrillation or other indications, anticoagulant medication), antihypertensives, and statins, are recommended to reduce the risk of stroke recurrence [2,3]. Medication adherence and persistence may be particularly challenging after stroke, however, because of difficulties caused by post-stroke physical and cognitive disability, particularly for people with more severe stroke [4], as well as the lack of immediate and obvious efficacy of essentially preventive medications.

It is vital that information materials about these stroke prevention medications are readable and appropriately presented for the layperson. Stroke disproportionately affects older people and those from less-advantaged socioeconomic groups [5], who are likely to have lower general and health literacy than the general population [6], and poor health literacy itself is known to be associated with higher all-cause mortality [7]. In addition, stroke survivors may have cognitive or communication difficulties $[8,9]$ and many have multiple comorbidities requiring a number of other medications [10]. If stroke survivors cannot readily access easy to read, accurate and appropriately written information, their ability to be an active participant in their own treatment and care will be compromised. This may affect medication persistence and adherence.

Whilst health care providers often provide verbal or printed written information about medications to supplement the standard 'patient information sheet' which is provided with the medication packet, stroke survivors and carers, in common with people experiencing other medical conditions, are increasingly turning to the internet, alongside other lay media sources (e.g. print and broadcast media) for additional information about their treatment options $[11,12]$. It is thus very important that online materials are written and presented comprehensibly for the layperson, and are accurate, unbiased, based on current evidence and guidelines, and designed to promote shared decision- 
making, especially as laypersons may have limited information-evaluation skills in relation to health information [11]. Few studies, however, have examined the readability and quality of online information about stroke. One study has found that online information about stroke (but not specifically about medication) is generally too complex for the layperson, but only examined readability rather than the reliability or quality of information [13]. Another study of online and other materials to communicate risk about thrombolysis for acute stroke also found that the information provided was too complex and often did not promote shared decision-making[14]. A further study [15] of websites specifically about vitamin K antagonist (warfarin/coumarin) therapy (which is commonly prescribed for a number of clinical problems, including stroke prevention) found that materials were accurate, but required high literacy levels. However, this study, like others, did not examine a wide range of sources, nor did it explore the extent to which the materials promoted shared decision-making. This is particularly important, given that laypersons who are searching the internet for health information may well be doing so in order to improve their ability to engage knowledgeably in decisions about their treatment and care. No studies to date have comprehensively examined online information about stroke, or have analysed the readability of information about stroke prevention medication. In addition, many studies have focused only on sources of information which have prima facie credibility, such as those produced by established health providers, rather than examining all relevant sources which are available to the lay Internet user. In particular, the content and readability of online news articles has not been examined, yet such articles may be a common source of lay information that is accessed opportunistically by stroke survivors and carers. The evaluation of online news articles also gives a snapshot of the quality and scope of the content of traditional broadcast and print media, given that articles are often hosted across both online and traditional media platforms.

The aim of this study was to review the readability and quality of online materials and online news articles which were likely to be accessed by patients or other laypeople in relation to secondary stroke prevention. The review focused on two drug classes: antiplatelets and oral anticoagulants, in [Type here] 
relation to stroke risk reduction rather than their effects for other conditions (e.g. venous thromboembolism).

The main objectives were to evaluate:

1. The readability of a sample of online materials

2. The quality and reliability of the materials

3. How the benefits and risks of the medications were presented.

\section{Methods}

Searches were conducted using Google, which is the most trusted [16] and widely used search engine in the world $[16,17]$, and which attracts approximately 100 billion web searches per month [17]. The Google UK search engine was used to identify materials that would be accessed during a typical online search from the UK, and separate searches were carried out using Google News to identify materials that were available via online news media outlets. Five separate searches were conducted for both Google UK and Google News. Search terms were stroke medications; warfarin after stroke; clopidogrel after stroke; anticoagulants after stroke; and antiplatelets after stroke. These terms were chosen to represent typical searches that a person after stroke, or their family member, might conduct, and included the generic names for the most commonly prescribed anticoagulant (warfarin) and antiplatelet drug (clopidogrel), as well as materials discussing anticoagulants, antiplatelets, and medications in general after stroke. The first 20 eligible websites for Google UK, and top 10 for Google News, which satisfied the inclusion and exclusion criteria were included. These numbers were chosen to mimic a realistic number of search results that a lay user might access, representing the first one or two pages of search results on a typical desktop computer. Google UK searches were not time-limited, but for Google News searches we initially limited to the past 6 months. For two of the searches, "Clopidogrel after stroke" and "Antiplatelets after stroke", the time period was extended to 24 months and 12 months respectively in order to 
obtain 10 relevant articles for each search. The Google UK search was conducted first, followed by the Google News search; any duplicates across the two searches were then excluded from the Google News search and replaced with the next item that met the criteria. This was done because most lay internet users would be likely to conduct searches using Google rather than Google News, but the additional Google News search gave a snapshot of content on broadcast and print media. Searches were carried out in July 2016 using a desktop computer linked to a UK university mainframe, by a student investigator (Author 2) using a student login. The student had not previously studied or worked in the field of stroke, or medication. Due to the way that Google, in common with other search engines, operates, this search strategy gave a non-reproducible 'snapshot' of the most commonly accessed information that was available at the time of the search; the identical search conducted at any other time, even with appropriate date limits, would generate at least some different results.

Searches excluded:

- Advertisements and other promoted materials

- Materials clearly intended primarily for health professionals or academic use (e.g. training materials, academic journal articles). When the search led to a website primarily for professionals but with a readily accessible link to information clearly labelled for laypersons, the latter was included. Where no such publicly focused information was linked, the resource was excluded.

- Materials written by stroke survivors, carers or other service users without any apparent professional input e.g. blogs and chatroom discussions

- Materials not written in English

All materials were saved from their source at the time of the search and classified according to the type of source. 
Materials were evaluated using the following methods:

1) Readability

The 'Simple Measure Of Gobbledygook' (SMOG) score [18], which is widely used in the assessment of health literature [19], was used to assess the number of years in education required to understand a sample of text. SMOG scores were calculated by copying and pasting the text into an electronic SMOG score calculator [20]. This calculated readability using sentence length and number of polysyllabic words, which was then converted into a 'grade score', denoting the number of years in full-time education that would be required to understand the text (broadly equivalent to chronological age minus 6 years). The SMOG tool selected provided a grade score which meant that someone of this reading ability would be able to fully comprehend the text, rather than merely understanding its general meaning. This was important since even minor misinterpretations or misreadings of written material about medication could have serious consequences for health.

\section{2) Quality and reliability}

Relevant text was rated against the DISCERN criteria [21], a 15-item instrument for judging the quality of written consumer health information on treatment choices. The DISCERN instrument has two main sections: reliability, and quality of information, plus an overall rating (see Table III). For section 2 of the DISCERN tool (quality of information), text was benchmarked against the then current edition of the UK Clinical Guideline for Stroke [22]. An overall score was given for each source using a 5-point scale in line with DISCERN user guidance [21]. A score of 5 was given if the quality criterion was completely fulfilled; scores of 4,3 or 2 were given if the criterion was partially fulfilled; a score of 1 was given if the quality criterion was not fulfilled at all.

3) Presentation of risks and benefits

[Type here] 
The DISCERN tool [21] includes only a limited overall assessment of whether the risks and benefits of treatment are described. As this is particularly pertinent when considering the use of preventive medication, a more detailed evaluation was conducted of the tone and content of this information in relation to locus of decision-making (e.g. whether the doctor, patient or both should decide whether to start the medication), implied certainty or uncertainty (e.g. whether the materials discussed the benefits of medication in terms of definitely 'preventing' or possibly 'reducing the risk of' another stroke), presentation of risks and benefits using numerical, verbal or pictorial/graphical methods, and emotive language.

Inclusion of final sources was based on the criteria described in the methods and was agreed by two researchers (RE and JG). Data extraction included all material within each source that pertained directly to antiplatelets and/or anticoagulants after stroke. Material that discussed other medications or treatments, or other aspects of life after stroke, was not extracted. Data extraction and ratings were performed by RE. A 10\% sample was rescored by JG with +/- 10\% agreement.

\section{Findings}

Materials accessed were from a variety of different types of source (see table I). Of the 100 websites, the British National Health Service (NHS) was the dominant source (27/100), either from the central website NHS Choices or from individual NHS provider organisations (e.g. hospital trusts). The charitable sector (e.g. The Stroke Association) contributed 24/100 of all sites included. 26/100 items were from types of source also found in the News search.

Of the 50 news items, 25 were from online versions of national tabloid newspapers; the remainder were from health websites and a range of other media outlets.

Typically, materials had SMOG scores that required a reading age of 17-18 years for full comprehension. For websites, the mean SMOG score was 14.5 (range 8.5-57.6). For news items, the mean SMOG score was 14.6 (range 11.2-21.8). (See Table II.) 
Quality appraisal of the materials is summarised in table III using the DISCERN criteria. Quality tended to be lower for news items (mean overall rating 2.67, range 1-5) than for websites (3.13, range 1-5). For all 15 DISCERN criteria there was at least one maximum ' 5 ' score for websites, but for $6 / 15$ criteria there were no news articles scoring 5 . Three items for the websites and seven items for the news items had mean scores of 2 or less. Two criteria (numbers 5 and 9) scored particularly poorly across both websites and news items: details of when the information reported was produced, and information on how the treatment works. For the websites, the highest mean DISCERN scores were seen for health charity website materials, from organisations such as the Stroke Association (www.stroke.org.uk) and the British Heart Foundation (www.bhf.org.uk), with a mean DISCERN score of 3.56 (range 3-4). NHS websites also had a higher mean DISCERN score (3.35, range $2-5$ ) than the overall score of 3.13 for all websites.

Presentation of risk, certainty, and emotive language is summarised in table IV. The benefits and risks of medication were overwhelmingly described in very general, non-numeric terms (e.g. 'will help prevent a stroke'). Where numerical values were given, this was most often expressed as relative risk reduction. Only five of the websites, and none of the news items, used visual depictions of risk and risk reduction such as graphs or pictograms.

Although the majority of websites, notably those from the charitable sector, directly referred to shared decision making, typically with statements that the individual should discuss the suitability of the medication with their doctor, it was notable that other treatment options (including the option of no treatment) were very rarely mentioned. Some other sources, including many from the NHS, indirectly implied that the individual had little or no choice or agency about whether or not to commence and continue the medication, via their use of terms such as 'must' or 'should', and they also generally lacked any mention of shared decision making or patient autonomy. $16 \%$ of web sources and $40 \%$ of news articles used at least one instance of emotive language. These illustrated either benefit or harm with terms such as 'slash', dramatic', and 'killer'. 


\section{Discussion}

This study shows that the interpretation of web-based information about anticoagulant and antiplatelet medication after stroke requires high levels of general literacy. While there are some high quality information sources, much of the available information is unreliable, of poor quality, does not promote shared decision making, and is sometimes emotionally laden. Perhaps unsurprisingly, news articles in particular are prone to using emotive language.

The overall highest quality sources tended to be from charities' websites such as the Stroke Association. These materials were typically easier to read than others, were based on accurate information, and took into account the need for patients' views and preferences to be considered in treatment choices. There were, however, notable examples of poorer quality material from some other sources which the layperson might expect to be authoritative, such as NHS providers. Although the information that such sources provided was generally accurate, in some cases the language was over-technical and hard to read; other sources used a paternalistic tone and language, which did not foster shared decision-making. Often, risks and benefits were mentioned but with no numerical information, and very few materials included graphical or pictorial illustrations to aid understanding.

Although we did not search specifically for 'easy-read' materials designed for comprehension by people with cognitive or language difficulties, none were retrieved by our general searches. The language of most of the commonly accessed materials was too complex for the general reader, especially those with limited health literacy, and would be likely to present particular challenges for people with cognitive or language difficulties. This is a particular concern given that many stroke survivors have some degree of cognitive and/or language difficulties.

Our study has several limitations. Although we included materials from any country, our search was confined to materials written in English and to those which were accessed via a UK web browser. 
We excluded advertisements and materials clearly designated for professional use, but it may be that laypersons would in fact access at least some of these materials. In the UK, direct advertising of prescription medications to laypeople is not permitted, and it is possible that a similar study in a country where it is (such as the USA) might yield very different findings. Our search strategy provided only a one-time snapshot of the available material that a layperson might access. We did not evaluate the materials blind, and our knowledge of the provenance of the materials may be a source of bias. We did not attempt to examine how stroke survivors or their carers actually understood and used these materials, and it is possible that at least some people, particularly those who are well-versed in using online materials, are adept at identifying and appraising higher- and lower-quality sources.

Our study concurs with previous findings $[13,14]$ that online information for laypeople about stroke is suboptimal. Since our review was conducted, a further study of online literature about heart failure [23] has identified similar issues with the readability and quality of materials. Although the provision of written information, including web-based sources, is only one element in supporting stroke survivors to make and continue with treatment choices, it is nonetheless an important one. Our study suggests, however, that it may be extremely challenging for stroke survivors to access easy to read, accurate and appropriately written information via the Internet that will assist them to participate in informed decisions about their treatment options in secondary prevention. This may affect uptake, persistence and adherence to these medications.

This study suggests that practitioners working with stroke survivors in primary and secondary care settings should ensure that they provide guidance and support to enable access to appropriate printed or Internet-based materials. It is clearly insufficient to expect stroke survivors and carers to rely on the readability and quality of the materials that they can access via the Internet without this guidance. Particular attention needs to be paid to the presentation of numerical data on risks and benefits in accessible forms, such as pictorial or graphical information. The limited emphasis on 
shared decision making is also an area of concern. Over-directive or emotive language is common, particularly in news items, and should be avoided. Practitioners, health care organisations and other information providers could make use of the SMOG and DISCERN tools to appraise any materials they provide or are developing. This would be optimally achieved in close collaboration with service user-led organisations and stroke survivors and carers themselves.

In future studies, consideration should be given to evaluating materials 'blind' to minimise bias. Further research could also usefully examine how well these materials are understood by stroke survivors and carers in practice, and develop ways of helping them to evaluate materials in order to base their treatment choices on accurate and unbiased information.

\section{Funding}

This work was supported by the University of Central Lancashire Undergraduate Research Internship Scheme 2016. JG is partly supported by the National Institute for Health Research Collaboration for Leadership in Applied Health Research and Care North West Coast. The views expressed are those of the authors and not necessarily those of the NHS, the NIHR or the Department of Health and Social Care. 


\section{References}

1. Sabate E. Adherence to Long-Term Therapies. Evidence for Action. 2003. Geneva; World Health Organization.

2. Intercollegiate Stroke Working Party. National Clinical Guideline for Stroke (5th edition). 2016. London; Royal College of Physicians.

3. Stroke Foundation. Clinical Guidelines for Stroke Management 2017. Melbourne, Australia.

4. Al AlShaikh S, Quinn T, Dunn W et al. Multimodal interventions to enhance adherence to secondary preventive medication after stroke: a systematic review and meta-analyses. Cardiovascular Therapeutics 2016;34 85-93.

5. Bray BD, Paley L, Hoffman A et al on behalf of the SSNAP Collaboration. Socioeconomic disparities in first stroke incidence, quality of care, and survival: a nationwide registry-based cohort study of 44 million adults in England. The Lancet Public Health 2018. DOI: https://doi.org/10.1016/S24682667(18)30030-6.

6. Patient Information Forum. Health Literacy and Health Information Producers - report. https://www.pifonline.org.uk/wp-content/uploads/2013/09/PiF-Health-Literacy-Report-WEB-NEWFINAL.pdf 2013.

7. Bostock S, Steptoe A. Association between low functional health literacy and mortality in older adults: longitudinal cohort study. BMJ 2012344 e1602

8. Douiri A, Rudd AG, Wolfe CDA. Prevalence of poststroke cognitive impairment South London Stroke Register 1995-2010. Stroke. 201344 138-145.

9. Ellis C, Hardy RY, Lindrooth RC et al. Rate of aphasia among stroke patients discharged from hospitals in the United States. Aphasiology 2018 32:9, 1075-1086.

[Type here] 
10. Gallacher KI, Batty GD, McLean G et al. Stroke, multimorbidity and polypharmacy in a nationally representative sample of 1,424,378 patients in Scotland: implications for treatment burden. BMC Medicine 2014 12, 151. http://doi.org/10.1186/s12916-014-0151-0

11. Cline RJW and Haynes KM. Consumer health information seeking on the Internet: the state of the art. Health Education Research 200116 (6) 671-692 https://doi.org/10.1093/her/16.6.671

12. Higgins $\mathrm{O}$, Sixsmith J, Barry MM et al. A literature review on health information seeking behaviour on the web: a health consumer and health professional perspective. Stockholm: European Centre for Disease Prevention and Control; 2011

13. Sharma N, Tridimas A, Fitzsimmons PR. A readability assessment of online stroke information. J Stroke Cerebrovasc Dis. 2014 Jul 23(6) 1362-7. doi: 10.1016/j.jstrokecerebrovasdis.2013.11.017.

14. Flynn D, Ford GA, Stobbart L et al. A review of decision support, risk communication and patient information tools for thrombolytic treatment in acute stroke: lessons for tool developers. $B M C$ Health Services Research 2013, 13: 225

15. Nasser S, Mullan J, Bajorek B (2012). Assessing the quality, suitability and readability of internetbased health information about warfarin for patients. The Australasian Medical Journal. 2012 5. 194203. 10.4066/AMJ.2012862.

16. Dutta, S. Access to the Web resources through Google: a brief study in popularity and service features. International Journal of Innovative Knowledge Concepts 2016. 2 (4).

17. McLean ACL, McLean AL, Kalff R et al. Google search queries about neurosurgical topics: Are they a suitable guide for neurosurgeons? World Neurosurgery 2016 90, 179-185.

18. McLaughlin GH. SMOG grading - a new readability formula. Journal of Reading. 1969, May 639646.

[Type here] 
19. Ley P, Florio T. The use of readability formulas in health care. Psychology, Health \& Medicine 19961 (1) 7-28.

20. http://www.wordscount.info/wc/jsp/clear/analyze_smog.jsp

21. Charnock D, Shepperd S, Needham G et al. DISCERN: an instrument for judging the quality of written consumer health information on treatment choices. Journal of Epidemiology and Community Health 1999 53(2), 105-111.

22. Intercollegiate Stroke Working Party (2012) National Clinical Guideline for Stroke (4th edition). London; Royal College of Physicians.

23. Cajita MI, Rodney T, Xu J et al. Quality and health literacy demand of online heart failure Information. J Cardiovasc Nurs. 2017 Mar/Apr 32(2) 156-164. doi: 10.1097/JCN.0000000000000324. 
Table I: Materials included classified by type of source.

\begin{tabular}{|c|c|c|}
\hline Type of source & Websites $(n=100)$ & News items $(n=50)$ \\
\hline NHS Choices & 7 & - \\
\hline Other NHS sources & 20 & - \\
\hline $\begin{array}{l}\text { Other health provider } \\
\text { organisations }\end{array}$ & 2 & - \\
\hline Charitable sector & 24 & - \\
\hline $\begin{array}{l}\text { National Institute for Health } \\
\text { and Care Excellence }\end{array}$ & 6 & - \\
\hline $\begin{array}{l}\text { Commercial companies e.g. } \\
\text { pharmaceutical }\end{array}$ & 6 & - \\
\hline $\begin{array}{l}\text { Practitioners' own } \\
\text { websites/materials }\end{array}$ & 5 & - \\
\hline Professional bodies & 4 & - \\
\hline Tabloid (national) & 6 & 25 \\
\hline Health website & 8 & 10 \\
\hline News agency & 1 & 4 \\
\hline Web based news source & 4 & 3 \\
\hline Local news website & 1 & 3 \\
\hline Broadsheet (national) & 3 & 2 \\
\hline $\begin{array}{l}\text { Broadcast media e.g. British } \\
\text { Broadcasting Corporation }\end{array}$ & 2 & 2 \\
\hline Magazine & 1 & 1 \\
\hline
\end{tabular}


Table II: Summary of SMOG scores for websites and news items

\begin{tabular}{|l|c|c|}
\hline & Websites $(\mathrm{n}=100)$ & News items $(\mathrm{n}=50)$ \\
\hline Average SMOG score & 14.49 & 14.62 \\
\hline Median SMOG score & 13.36 & 14.41 \\
\hline Highest SMOG score & 57.63 & 21.84 \\
\hline Lowest SMOG score & 8.53 & 11.21 \\
\hline Average age of understanding & 18.49 & 18.62 \\
\hline Median age of understanding & 17.36 & 18.41 \\
\hline
\end{tabular}


Table III - DISCERN scores for Website and News literature

\begin{tabular}{|c|c|c|}
\hline & $\begin{array}{l}\text { Websites } \\
\text { Mean } \\
\text { (range) }\end{array}$ & $\begin{array}{l}\text { News items } \\
\text { Mean } \\
\text { (range) }\end{array}$ \\
\hline \multicolumn{3}{|l|}{ Section 1: Reliability } \\
\hline 1. Are the aims clear? & $4(2-5)$ & $3(2-4)$ \\
\hline 2. Does it achieve its aims? & $4(1-5)$ & $4(3-5)$ \\
\hline 3. Is it relevant? & $4(2-5)$ & $4(2-5)$ \\
\hline $\begin{array}{l}\text { 4. Is it clear what sources of information were used to } \\
\text { compile the publication (other than the author or } \\
\text { producer)? }\end{array}$ & $2(1-5)$ & $3(1-4)$ \\
\hline $\begin{array}{l}\text { 5. Is it clear when the information used or reported in } \\
\text { the publication was produced? }\end{array}$ & $2(1-5)$ & $1(1-4)$ \\
\hline 6. Is it balanced and unbiased? & $4(2-5)$ & $4(2-5)$ \\
\hline $\begin{array}{l}\text { 7. Does it provide details of additional sources of } \\
\text { support and information? }\end{array}$ & $3(1-5)$ & $2(1-4)$ \\
\hline 8. Does it refer to areas of uncertainty? & $4(1-5)$ & $2(1-5)$ \\
\hline \multicolumn{3}{|l|}{$\begin{array}{l}\text { Section 2: How good is the quality of the information on } \\
\text { treatment choices? }\end{array}$} \\
\hline 9. Does it describe how each treatment works? & $2(1-5)$ & $1(1-3)$ \\
\hline 10. Does it describe the benefits of each treatment? & $3(1-5)$ & $3(1-5)$ \\
\hline 11. Does it describe the risks of each treatment? & $3(1-5)$ & $2(1-5)$ \\
\hline
\end{tabular}




\begin{tabular}{|c|c|c|}
\hline $\begin{array}{l}\text { 12. Does it describe what would happen if no treatment } \\
\text { is used? }\end{array}$ & $3(1-5)$ & $4(1-5)$ \\
\hline $\begin{array}{c}\text { 13. Does it describe how the treatment choices affect } \\
\text { overall quality of life? }\end{array}$ & $3(1-5)$ & $3(1-5)$ \\
\hline $\begin{array}{l}\text { 14. Is it clear that there may be more than one possible } \\
\text { treatment choice? }\end{array}$ & $3(1-5)$ & $2(1-3)$ \\
\hline 15. Does it provide support for shared decision-making? & $3(1-5)$ & $2(1-5)$ \\
\hline Section 3: Overall rating of the publication & & \\
\hline Based on the answers to all of the above questions, rate the & & \\
\hline overall quality of the publication as a source of information & & \\
\hline about treatment choices. (arithmetic mean of Scores 1-15) & & \\
\hline
\end{tabular}


Table IV: Presentation of risk, certainty and emotive language in websites and news sources

\begin{tabular}{|c|c|c|}
\hline & $\begin{array}{l}\text { Google UK sources: mean } \\
\text { occurrences across } 100 \\
\text { sources (\% of sources) }\end{array}$ & $\begin{array}{l}\text { News items: mean occurrences } \\
\text { across } \mathbf{5 0} \text { sources (\% of } \\
\text { sources) }\end{array}$ \\
\hline $\begin{array}{l}\text { Risks Presented (e.g. } \\
\text { adverse drug reactions) }\end{array}$ & & \\
\hline In words & $3.75(73)$ & $1.84(62)$ \\
\hline As relative risk & $0.28(14)$ & $0.04(4)$ \\
\hline As absolute frequency & $0.06(4)$ & $0.00(0)$ \\
\hline $\begin{array}{l}\text { As number needed to harm } \\
\text { (NNH) }\end{array}$ & $0.44(14)$ & $0.00(0)$ \\
\hline As graph or pictogram & $0.18(4)$ & $0.00(0)$ \\
\hline $\begin{array}{l}\text { Benefits Presented (e.g. } \\
\text { reduction in stroke risk) }\end{array}$ & & \\
\hline In words only & $2.46(86)$ & $2.40(90)$ \\
\hline As relative risk reduction & $0.34(15)$ & $0.60(32)$ \\
\hline As absolute frequency & $0.34(6)$ & $0.04(4)$ \\
\hline $\begin{array}{l}\text { As number needed to treat } \\
\text { (NNT) }\end{array}$ & $0.05(6)$ & $0.00(0)$ \\
\hline As graph or pictogram & $0.29(5)$ & $0.00(0)$ \\
\hline $\begin{array}{l}\text { Discussion of decision to } \\
\text { take medication or not }\end{array}$ & & \\
\hline 'Must' take medication & $1.3(46)$ & $0.3(20)$ \\
\hline 'Should' take medication & $2.64(59)$ & $1.2(68)$ \\
\hline Shared decision making & $2.26(57)$ & $0.72(40)$ \\
\hline
\end{tabular}

[Type here] 


\begin{tabular}{|l|r|r|}
\hline 'Will' prevent or reduce risk & $2.28(78)$ & $1.22(64)$ \\
\hline 'May' prevent or reduce risk & $0.73(36)$ & $0.82(54)$ \\
\hline Incidence of emotive & $0.34(16)$ & $0.68(40)$ \\
language & "Aspirin a day could & "Taking aspirin after a mini \\
language (capitalisations in & dramatically cut cancer risk, & STROKE can slash risk of major \\
original sources) & says biggest study yet" & one by EIGHTY per cent" \\
& "ROUTINE DRUG & "An aspirin a day keeps death at \\
& COMBINATION IS A KILLER" & bay" \\
\hline
\end{tabular}

